\title{
Thymoquinone subdues tumor growth and potentiates the chemopreventive effect of 5 -fluorouracil on the early stages of colorectal carcinogenesis in rats
}

\author{
This article was published in the following Dove Press journal: \\ Drug Design, Development and Therapy \\ II July 2016 \\ Number of times this article has been viewed
}

\author{
Osama Adnan Kensara ${ }^{1, *}$ \\ Adel Galal El-Shemi ${ }^{2,3, *}$ \\ Amr Mohamed Mohamed 2,4 \\ Bassem Refaat ${ }^{2}$ \\ Shakir Idris ${ }^{2}$ \\ Jawwad Ahmad ${ }^{2}$ \\ 'Department of Clinical Nutrition, \\ Faculty of Applied Medical Sciences, \\ Umm Al-Qura University, Holy \\ Makkah, Saudi Arabia; ${ }^{2}$ Department \\ of Laboratory Medicine, Faculty of \\ Applied Medical Sciences, Umm \\ Al-Qura University, Holy Makkah, \\ Saudi Arabia; ${ }^{3}$ Department of \\ Pharmacology, Faculty of Medicine, \\ Assiut University, Assiut, Egypt; \\ ${ }^{4}$ Department of Animal Medicine, \\ Faculty of Veterinary Medicine, Assiut \\ University, Assiut, Egypt \\ *These authors contributed equally \\ to this work
}

\begin{abstract}
Colorectal cancer (CRC) is one of the most prevalent cancers and has a high mortality rate. Insensitivity and the limited therapeutic efficacy of its standard chemotherapeutic drug, 5-fluorouracil (5-FU), represents an important challenge in CRC treatment. The robust antitumor properties of thymoquinone (TQ), the main bioactive constituent of Nigella sativa, have recently been demonstrated on different cancers. We investigated whether TQ could potentiate the chemopreventive effect of 5-FU to eradicate the early stages of CRC and elucidated its underlying mechanisms. An intermediate-term (15 weeks) model of colorectal tumorigenesis was induced in male Wistar rats by azoxymethane (AOM), and the animals were randomly and equally divided into five groups: control, AOM, AOM/5-FU, AOM/TQ, and AOM/5-FU/TQ. TQ $(35 \mathrm{mg} / \mathrm{kg} / \mathrm{d} ; 3 \mathrm{~d} / \mathrm{wk}$ ) was given during the seventh and 15 th weeks post-AOM injection, while 5 -FU was given during the ninth and tenth weeks $(12 \mathrm{mg} / \mathrm{kg} / \mathrm{d}$ for 4 days; then $6 \mathrm{mg} / \mathrm{kg}$ every other day for another four doses). At week 15, the resected colons were subjected to macroscopic, histopathological, molecular, and immunohistochemical examinations. Interestingly, 5-FU/TQ combination therapy resulted in a more significant reduction on AOM-induced colorectal tumors and large aberrant crypts foci than treatment with the individual drugs. Mechanistically, 5-FU and TQ remarkably cooperated to repress the expression of procancerous $W n t, \beta$-catenin, $N F-\kappa B$, $C O X-2$, iNOS, VEGF, and TBRAS and upregulate the expression of anti-tumorigenesis $D K K-1$, $C D N K-1 A, T G F-\beta 1$, TGF- $\beta$ RII, Smad4, and GPx. Overall, our findings present the first report describing the in vivo enhancement effect of combined TQ and 5-FU against early stages of $\mathrm{CRC}$; however, further studies are required to determine the value of this combination therapy in an advanced long-term model of CRC and also to realize its clinical potential.
\end{abstract}

Keywords: colorectal tumors, thymoquinone, 5-fluorouracil, combination therapy, rats

\section{Introduction}

Colorectal cancer (CRC) is one of the most prevalent life-threatening malignant diseases across the world. ${ }^{1,2}$ According to the World Health Organization's International Agency for Research on Cancer, CRC is recognized as the third most frequent cancer in men, the second most frequent inwomen, and the fourth leading cause of cancer-related deaths worldwide. ${ }^{2}$ Despite the extensive efforts that have been made to improve its diagnostic and screening tools, the limited therapeutic efficacy of its current therapy represents the most important challenge in CRC management. In this aspect, 5-fluorouracil (5-FU)-based therapy, either alone or in combination with other cytotoxic agents (eg, irinotecan, leucovorin, or oxaliplatin), remains the standard 
chemotherapeutic approach., ${ }^{3,4}$ Overall, 5-FU still exhibits limited efficacy with a low tumor response rate ranging between $7 \%$ and $17 \%$ with monotherapy and $35 \%$ and $39 \%$ when given with other chemotherapeutic agents. ${ }^{4,5}$ More importantly, although the recent addition of new targeted agents, such as bevacizumab and cetuximab, to the standard chemotherapy provides hope for more effective therapy in advanced CRC, they have shown only modest benefit and they are also subject to both primary and secondary resistance like traditional chemotherapy, which ultimately leads to treatment failure. ${ }^{4}$ Thus, development of potential alternative combinational therapeutic strategies is of paramount importance to improve the prognosis and the curing rate of this deadly cancer. To that end, thymoquinone (TQ) is being pursued as one of the attractive agents in this setting. 6,7

Several natural products and nutraceuticals have shown increasing health benefits when used as adjuvants or alternative remedies to conventional drugs. ${ }^{1,6}$ For instance, Nigella sativa, or black seed, and its main bioactive constituent "TQ" have been shown to exert pleiotropic pharmacological actions and biological activities including antitumor, anti-inflammatory, immunomodulatory, antifibrotic, analgesic, antihypertensive, antidiabetic, antimicrobial, antioxidant, and tissue protective properties in a variety of medical disorders. ${ }^{6-9}$ As an anticancer agent, TQ's potent antitumorigenic cellular and molecular effects on the activities of various precancerous and tumor suppressor genes/ molecules that impact tumor cell proliferation, differentiation, angiogenesis, apoptosis, invasion, and other important aspects of tumorigenesis have recently attracted a great deal of attention for the treatment of different cancers. ${ }^{9,10}$ Its favorable chemopreventive and tumoricidal properties have been observed in a variety of in vitro and in vivo models of human cancers. ${ }^{11-13}$ More importantly, TQ was shown to chemosensitize and augment the cytotoxic effects of the conventional chemotherapeutic drugs on cancer cells. ${ }^{11-14}$ Furthermore, some clinical trials on different diseases have shown TQ's promising safety profile, suggesting its potential to be developed as a novel drug in clinical aspect., ${ }^{9,10,15}$

Taken together, TQ may be a potential adjuvant agent in therapy of CRC, especially in the chemoresistance subset. ${ }^{16}$ Therefore, the present study aimed to investigate whether combined therapy with TQ would improve and potentiate the anti-CRC effect of 5-FU on colorectal neoplasia induced by an intermediate-term model of azoxymethane (AOM) in rats, and to elucidate the possible mechanisms that would mediate such beneficial synergistic interaction between the two drugs. AOM-induced colorectal tumors and carcinogenesis in rats and mice have been proven to be outstanding rodent models that closely mirror the phases and features of human CRC (aberrant crypts foci [ACF]-adenoma-adenocarcinoma and carcinoma sequence) in a time-dependent manner post AOM injection, and commonly used to assess new chemopreventive and therapeutic strategies and to provide new insights into the pathophysiologic mechanisms and risk factors of human CRC. ${ }^{17,18}$ Our findings show that though monotherapy with either TQ or 5-FU results in a significant chemopreventive effect on this model, their combination exhibits a more significant efficacy to repress the morphological, histopathological, and molecular changes that were observed in this model. Further studies are still essential to realize the potential clinical value of this combination in patients with early CRC disease, as well as to illustrate its possible usefulness in advanced stages of this dark cancer.

\section{Materials and methods Drugs and chemicals}

TQ (2-isopropyl-5-methyl-1,4-benzoquinone), AOM, and 5-FU were purchased from Sigma-Aldrich Co. (St Louis, MO, USA). Unless otherwise stated, all other chemicals used were of the highest commercial grade.

\section{Animals, induction of colorectal tumorigenesis, and treatment approach}

All experimental protocols and procedures of the current study were approved by the Institutional Animal Care and Use Committee of the University of Umm Al-Qura, and were in accordance with The US Public Health Service Policy on Humane Care and Use of Laboratory Animals. Sixty adult male Wistar rats of $230 \pm 20 \mathrm{~g}$ body weight were housed in sterile polyvinyl cages (five rats per cage) at a controlled temperature of $22^{\circ} \mathrm{C} \pm 3{ }^{\circ} \mathrm{C}$ with a 12-hour light/dark cycle, and maintained on standard laboratory pellet diet and water ad libitum. The rats were allowed to acclimatize for 1 week before starting the experiments. For induction of colorectal tumorigenesis, AOM was dissolved in normal saline and injected subcutaneously at a dose of $15 \mathrm{mg} / \mathrm{kg}$, once weekly for 2 weeks as previously described. ${ }^{18}$ According to the subsequent treatment schedules, the rats were randomly categorized into the following five groups (12 rats/group): group 1 (normal controls), not injected with AOM and received only normal saline; group 2 (AOM group), AOM-injected rats and left without treatment; group 3 (AOM/5-FU group), AOM-injected rats and then treated with 5-FU; group 4 (AOM/TQ group), AOM-injected rats and then treated with TQ; and group 5 (AOM/5-FU/TQ group), AOM-injected 
rats and then treated with 5-FU plus TQ. In the designated groups, 5-FU was freshly prepared in normal saline and injected intraperitoneally during the ninth and tenth weeks post AOM injection in a dosage regimen similar to that used in the treatment of human CRC $(12 \mathrm{mg} / \mathrm{kg} / \mathrm{d}$ for four successive days, then $6 \mathrm{mg} / \mathrm{kg}$ every other day for four doses), while TQ was freshly prepared by dissolving it in $0.5 \%$ dimethylsulfoxide followed by dilution using olive oil, and then given orally by gastric gavage at the following dosage regimen: $35 \mathrm{mg} / \mathrm{kg} / \mathrm{d}, 3 \mathrm{~d} / \mathrm{wk}$; starting from the seventh week post AOM injection and continued till the end of the study (ie, week 15). The dissolving process and dose of TQ were chosen on the basis of pilot experiments and of previously published reports..$^{10,19}$

\section{Blood sampling, whole colon resection, and macroscopic examination for grown tumors and large aberrant crypts foci}

At the end of the experimental period, rats of the different groups were weighed, fasted overnight, and then euthanized under general anesthesia using diethyl (Thermo Fisher Scientific, Waltham, MA, USA). Following euthanasia, the whole blood sample was collected from vena cava into a plane tube and used to measure the serum levels of liver function enzymes (alkaline phosphatase, alanine aminotransferase, and aspartate aminotransferase) and kidney function tests (creatinine, urea, and blood urea nitrogen) by using a Cobas e411 analyzer (Hoffman-La Roche Ltd., Basel, Switzerland) according to the manufacturer's instructions. Subsequently, the whole colon from rectum to cecum was gently resected, flushed with phosphate-buffered saline, and slit open longitudinally. The surface area of each isolated colon (length $\times$ width in $\mathrm{cm}^{2}$ ) was measured, followed by immersing the whole colon in $10 \%(\mathrm{v} / \mathrm{v})$ neutralized formalin overnight between layers of filter papers with the mucosa on the upper side. The grown tumors on the mucosa of the isolated colons were blindly counted by naked eye by two observers. Next, the colon was cut into three portions: proximal, middle, and distal segments. Each segment was stained with $0.2 \%$ methylene blue solution for $1.5-2$ minutes, placed on a microscope slide with the mucosal side upward, and examined under a dissecting microscope to count both small tumors that were not detected by the naked eye, and large ACF (containing four or more aberrant crypts) according to previously established criteria. ${ }^{20}$ Thereafter, by using a microfeather scalpel blade and under the dissecting microscope, the colorectal specimens that had tumors and $\mathrm{ACF}$ were excised from the surrounding normal colorectal tissues and subsequently prepared for histopathological, molecular, enzyme-linked immunosorbent assay (ELISA), and immunohistochemical (IHC) examinations.

\section{Histopathological examination}

The tissue specimens were first immersed in $80 \%$ ethanol for removing the methylene blue and then embedded in paraffin, sectioned (4-5 $\mu \mathrm{m}$ tissue sections), de-paraffinized, and stained with hematoxylin and eosin by using conventional methods. The stained colorectal tissue sections were microscopically examined for the presence of $\mathrm{ACF}$, colonic adenomas, and adenocarcinomas. Based on the crypt architecture and nuclear features, ACF were microscopically classified into hyperplastic ACF (no dysplasia) or dysplastic ACF (elongated, crowded, and pseudo-stratified nuclei, increased nucleus-to-cytoplasm ratio, reduced number of goblet cells, back-to-back glands, and markedly decreased interglandular stroma) as previously described. ${ }^{21}$ A colonic adenoma consists of proliferative and hyperplastic glands, while colonic adenocarcinoma is composed of dysplastic glands invading the submucosa and muscular layers. ${ }^{17,21}$ In addition, since the so-called mucin-depleted foci (MDFs) were recently recognized as a better precancerous predictor of colorectal carcinogenesis than ACF, colorectal tissue slides of the different groups were subsequently stained with Alcian blue to stain mucin and detect these MDFs as previously desribed. ${ }^{17}$

\section{RNA extraction, cDNA synthesis, and gene expression analysis}

To explore the underlying molecular mechanisms that could be involved in the induction or attenuation of this colorectal tumorigenesis model, the colorectal mRNA levels of Wnt, $\beta$-catenin, $N F-\kappa B$, and $C O X-2$ (as representatives of procancerous genes) and those of $D K K-1, C D N K-1 A, T G F-\beta 1$, and Smad4 (as representative of tumor suppressor/anti-cancerous genes) were assessed in all animal groups. First, the colorectal specimens were homogenized in RNAlater solution (Ambion, Waltham, MA, USA), and then the total RNA was isolated by using the Purelink RNA mini kit (Thermo Fisher Scientific), following the manufacturer's instructions. The quality and the quantity of the extracted RNA were measured by the Nanodrop equipment (BioSpec-nano; Shimadzu Corporation, Kyoto, Japan). Next, up to $200 \mathrm{ng}$ of the extracted total RNA was reverse-transcripted to cDNA by using a high-capacity RNA-to-cDNA reverse transcription kit (Thermo Fisher Scientific) according to the manufacturer's instructions. Finally, quantitative real-time polymerase 
chain reaction (qRT-PCR) was conducted. All reactions were performed in triplicate by using the SYBR Green PCR Master Mix (Thermo Fisher Scientific), an ABI 7500 RT-PCR system (Thermo Fisher Scientific), and the $2^{-\Delta \Delta C T}$ method, as previously described. ${ }^{22}$ Briefly, the reactions were performed in triplicate in a total volume of $20 \mu \mathrm{L}$ each containing $10 \mu \mathrm{L}$ SYBR Green PCR master mix, $7 \mu \mathrm{L}$ DNase/ RNase-free water, $1 \mu \mathrm{L}$ ( 5 pmol) of each primer, and $1 \mu \mathrm{L}$ (25 ng) cDNA, and the amplification was conducted under the following conditions: 40 cycles, 15 seconds at $95^{\circ} \mathrm{C}$, and 1 minute at $65^{\circ} \mathrm{C}$. The data were analyzed using a comparative threshold cycle $(\mathrm{Ct})$ technique, normalized against the $\mathrm{Ct}$ values of $\beta$-actin, and expressed as fold-change compared with the normal control group. The nucleotide primer sequences of rat's Wnt (NM_001105714.1), $\beta$-catenin (AF397179.1), $N F-\kappa B$ (NM_001008349.1), COX-2 (AF233596.1), DKK-1 (NM_001106350.1), CDNK-1A (NM_080782.3), TGF- $\beta 1$ (NM_021578.2), and Smad4 (NM_019275.3), in addition to $\beta$-actin (NM_031144.3) as an internal reference (housekeeping) gene, are summarized in Table 1.

\section{Enzyme-linked immunosorbent assay}

ELISA was used to quantitatively measure the colorectal expression pattern of $\beta$-catenin, TGF- $\beta 1$, and $C O X-2$ at their protein level. Furthermore, the colorectal concentrations of vascular endothelial growth factor (VEGF, as an index of tumor angiogenesis), glutathione peroxidase (GPx, as an index of antioxidant status), and thiobarbituric acid reactive substances (TBARS, as an index of lipid peroxidation) were also measured by the ELISA technique. For the assays, the colorectal tissue specimens of the different studied groups were homogenized in RIPA lysis buffer containing protease inhibitors (Santa Cruz Biotechnology Inc., Dallas, TX, USA), centrifuged, and then their harvested supernatants were stored in $-20^{\circ} \mathrm{C}$ till use. During the assays, the total protein concentration in each sample was adjusted, and the concentrations of the candidate molecules were measured by using commercial ELISA kits (Cusabio, Hubei, People's Republic of China, for $\beta$-catenin, TGF- $\beta 1$, COX-2, and VEGF; and Cayman Chemical, Ann Arbor, MI, USA for GPX and TBARS) following the manufacturers' protocols.

\section{Immunohistochemistry analysis}

IHC staining for TGF- $\beta 1$ and the related TGF- $\beta$ RII and Smad4, $\beta$-catenin, and inducible nitric oxide synthase (iNOS) was performed on the colorectal paraffin tissue sections of the different animal groups and following the conventional protocol. The primary antibodies (1:100; Santa-Cruz Biotechnology Inc.) used were as follows: polyclonal goat IgG antibodies against rat's $\beta$-catenin (C-18), TGF- $\beta 1$ (C-16), and Smad4 (C-20); and polyclonal rabbit IgG antibodies against rat's TGF- $\beta$ RII (L-21) and iNOS (N-20). Anti-goat or anti-rabbit avidin-biotinylated horseradish peroxidase (1:200; Santa-Cruz Biotechnology Inc.) were used as secondary antibodies. Staining was developed by $3,3^{\prime}$-diaminobenzidine chromogen substrate and counterstained with Gill's hematoxylin. The intensity of staining was assessed by using the $H$-score formula as follows: $H$-score $=$ $\Sigma P_{i}(i+1)$, where $i$ represents the intensity of positive stained cells $(0=$ negative, $1=$ weak, $2=$ moderate, and $3=$ strong $)$ and $P_{i}$ is the percentage $(0 \%-100 \%)$ of positive-stained cells. ${ }^{23}$

\section{Statistical analysis}

Results are expressed as mean $\pm \mathrm{SD}$. The statistical significance of differences between the values of the different groups was determined using one-way analysis of variance, with post hoc comparisons using Dunnett's multiple comparison test. The differences between data were considered to be statistically significant when $P<0.05$, and to be very significant when $P<0.01$.

Table I Primer sequences used in the real-time quantitative PCR for detection of the transcription activities of Wnt, $\beta$-catenin, NF- $k B$, COX-2, DKK-I, CDNK-IA, TGF- $\beta$ I, Smad4, and $\beta$-actin genes including the corresponding gene's accession numbers

\begin{tabular}{|c|c|c|}
\hline Gene & Forward & Reverse \\
\hline Wnt (NCBI: NM_00I I057 I4.I) & $5^{\prime}$ AGC TGG GTT TCT GCT ACG TT 3' & $5^{\prime}$ AAT CTG TCA GCA GGT TCG TG $3^{\prime}$ \\
\hline$\beta$-catenin (NCBI: AF397I79.I) & $5^{\prime}$ TTC CTG AGC TGA CCA AAC TG $3^{\prime}$ & $5^{\prime}$ GCA CTA TGG CAG ACA CCA TC $3^{\prime}$ \\
\hline NF-kB (NCBI: NM_00I008349.I) & 5' CAG AGC TGG CAG AGA GAC TG 3' & $5^{\prime}$ TAC GAA GGA GAC TGC CAC TG 3' \\
\hline COX-2 (NCBI: AF233596.I) & $5^{\prime}$ AAT CGC TGT ACA AGC AGT GG $3^{\prime}$ & 5' GCA GCC ATT TCT TTC TCT CC $3^{\prime}$ \\
\hline DKK-I (NCBI: NM_00II06350.I) & 5' ATT CCA GCG CTG TTA CTG TG 3' & 5' GAA TTG CTG GTT TGA TGG TG 3' \\
\hline CDNK-IA (NCBI: NM_080782.3) & $5^{\prime}$ AGA AGG GAA CGG GTA CAC AG 3' & $5^{\prime}$ ACC CAT AAG AAG GGC AGT TG 3' \\
\hline TGF- $\beta$ I (NCBI: NM_02I578.2) & 5' GGTGGACCGCAACAACGCAATCTA 3' & 5' GGGTGGCCATGAGGAGCAGGAA 3' \\
\hline Smad4 (NCBI: NM_019275.3) & $5^{\prime}$ CCACCAACTTCCCCAACATT $3^{\prime}$ & 5' TGCAGTCCTACTTCCAGTCCAG 3' \\
\hline$\beta$-actin (NCBI: NM_03 I | 44.3) & $5^{\prime}$ CGG TCA GGT CAT CAC TAT CG 3' & 5' TTC CAT ACC CAG GAA GGA AG 3' \\
\hline
\end{tabular}

Abbreviation: $\mathrm{PCR}$, polymerase chain reaction. 


\section{Results}

\section{Effects of TQ, 5-FU, and their combination therapy on the development of colorectal gross tumors and large ACF}

In the present study, the therapeutic efficacy of monotherapy and combination therapy with TQ and 5-FU on early colorectal tumorigenesis and tumor growth was evaluated in an intermediate-term model (15 weeks) of AOM-induced colorectal carcinogenesis in rats. In this model, rats that received AOM and were left without treatment developed a significant number of gross tumors and distortions on their colorectal mucosa (Table 2; Figure 1B[i]) compared to the colorectal tissues of normal controls (Table 2; Figure 1A[i]). However, treatment of these AOM-injected rats with either 5-FU (Table 2; Figure 1C[i]) or TQ (Table 2; Figure 1D[i]) led to a significantly decreased number of the grown tumors and topographic mucosal alterations. Importantly, a significant synergistic interaction was achieved via 5-FU/TQ combination therapy, as shown by the lowest number of grown colorectal tumors (Table 2; Figure 1E[i]). Similarly, examination of the resected colons by the dissecting microscope following methylene blue staining showed the presence of several microtumors and larger ACF in the colorectal tissues of AOM-injected rats and left without treatment (Table 2; Figure 1B[ii]), and monotherapy with either 5-FU (Table 2; Figure 1C[ii]) or TQ (Table 2; Figure 1D[ii]) markedly reduced the total number of microtumors and larger ACF as compared to the AOM group (Table 2). More interestingly, the colorectal mucosal architecture was more preserved and the total number of microtumors and larger ACF was further and significantly reduced in the TQ/5-FU combined treatment group (Table 2; Figure 1E[ii]) compared to 5-FU or TQ treatment alone. The histopathological findings (Figure 1) were also consistent with the macroscopic/microscopic observations and showed the presence of many large ACF ( $>4$ crypts/focus) with hyperplastic and dysplastic features (Figure 1B[iii]), precancerous MDFs (Figure S1), as well as multiple tubular adenomas in the colorectal tissues of rats injected with $\mathrm{AOM}$ and left without any treatment (AOM group) (Figure 1B[iii]). By contrast, treatment of these AOM-injected rats with 5-FU (Figure 1C[iii]), TQ (Figure 1D[iii]), or 5-FU plus TQ (Figures 1E[iii] and S1) attenuated the development of such pre-neoplastic large ACF and MDF, as well as tubular adenomas. And the highest attenuating effect was also observed with 5-FU/TQ dual therapy. Taken together, these results indicate that therapy with TQ not only attenuated CRC initiation but also had the capability to enhance the tumoricidal and chemopreventive efficacy of 5-FU in this disease modality.

\section{qRT-PCR findings of gene expression study}

To understand the possible underlying mechanisms of the observed chemopreventive effects of TQ and 5-FU therapy on this rodent model of early stages of CRC, gene expression study was performed for four procancerous genes (Wnt, $\beta$-catenin, $N F-\kappa B$, and $C O X-2$ ) and for four anticancerous/tumor-suppressor genes (DKK-1,CDNK-1A, $T G F-\beta 1$, and Smad4), which collectively play an important role in controlling CRC development and progression.

Table 2 Effects of thymoquinone (TQ) and/or 5-fluorouracil (5-FU) therapy

\begin{tabular}{|c|c|c|c|c|c|}
\hline Parameter & Normal group & AOM group & AOM/5-FU group & AOM/TQ group & AOM/5-FU/TQ group \\
\hline Body weight (g) & $231.5 \pm 20$ & $221.9 \pm 23$ & $238.4 \pm 13.6$ & $237.8 \pm 24$ & $231.8 \pm 21$ \\
\hline Colon surface area $\left(\mathrm{cm}^{2}\right)$ & $19.1 \pm 2.2$ & $18.89 \pm 3.43$ & $19.81 \pm 1.84$ & $20.7 \pm 2.72$ & $20.3 \pm 3.7$ \\
\hline \multicolumn{6}{|l|}{ Tumor count } \\
\hline Gross & N/A & $12.5 \pm 3.21$ & $8.7 \pm 2.9^{a}$ & $9.1 \pm 2.5^{a}$ & $7.3 \pm 1.3^{b-d}$ \\
\hline Dissecting microscope & $N / A$ & $17.36 \pm 4.6$ & $8.8 \pm 1.75^{\mathrm{a}}$ & $7.9 \pm 2.8^{a}$ & $6.1 \pm 1.4^{b-d}$ \\
\hline Total & $N / A$ & $29.16 \pm 2.92$ & $|6.66 \pm 4.4|^{\mathrm{a}}$ & $17.5 \pm 2.1^{\mathrm{a}}$ & $13.8 \pm 2.8^{\mathrm{b}-\mathrm{d}}$ \\
\hline Large ACF count & $\mathrm{N} / \mathrm{A}$ & $45.7 \pm 5.4$ & $23.2 \pm 3.7^{\mathrm{a}}$ & $25.0 \pm 4.0^{\mathrm{a}}$ & $16.4 \pm 3.1^{b-d}$ \\
\hline AST (U/L) & $92.4 \pm 24.2$ & $105.8 \pm 26.7$ & $109 \pm 21.6$ & $100 \pm 23.2$ & $104.8 \pm 13.1$ \\
\hline ALT (U/L) & $67.6 \pm 2.4$ & $71.2 \pm 6.7$ & $68.7 \pm 4.1$ & $66.7 \pm 16.9$ & $65.2 \pm 15.7$ \\
\hline ALP (IU/L) & $122.6 \pm 1 \mid .2$ & $125.7 \pm 9.7$ & $122.8 \pm 12.4$ & $124.3 \pm 11.9$ & $|2| .6 \pm \mid 1.1$ \\
\hline Creatinine (mg/dL) & $0.22 \pm 0.03$ & $0.23 \pm 0.06$ & $0.23 \pm 0.05$ & $0.20 \pm 0.02$ & $0.21 \pm 0.04$ \\
\hline Urea (mg/dL) & $48.6 \pm 5.1$ & $50.3 \pm 4.3$ & $50.6 \pm 9.5$ & $48.8 \pm 6.2$ & $49.3 \pm 7.4$ \\
\hline BUN (mg/dL) & $22.2 \pm 2.4$ & $24.4 \pm 1.9$ & $24.3 \pm 4.4$ & $21.2 \pm 3.8$ & $22.5 \pm 3.4$ \\
\hline
\end{tabular}

Notes: The table shows the effect on the body weight, colon surface area (length $\times$ width in $\mathrm{cm}^{2}$ ), numbers of grown tumors and large aberrant crypts foci (ACF), liver enzymes (AST, ALT, and ALP), and renal function parameters (creatinine, urea, and BUN) in azoxymethane (AOM)-induced colorectal tumors in rats. The gross colorectal tumors were counted by the naked eye, while both microtumors and large ACF (containing four or more aberrant crypts) were counted under a dissecting microscope after methylene blue staining. Data are represented as mean $\pm S D$. ${ }^{a} P<0.05$ vs $A O M$ group. ${ }^{b} P<0.05$ vs $A O M / 5-F U$ group. ${ }^{c} P<0.05$ vs $A O M / T Q$ group. ${ }^{d} P<0.0$ I vs $A O M$ group. Abbreviations: N/A, not applicable; AST, aspartate aminotransferase; ALT, alanine aminotransferase; ALP, alkaline phosphatase; BUN, blood urea nitrogen. 
A
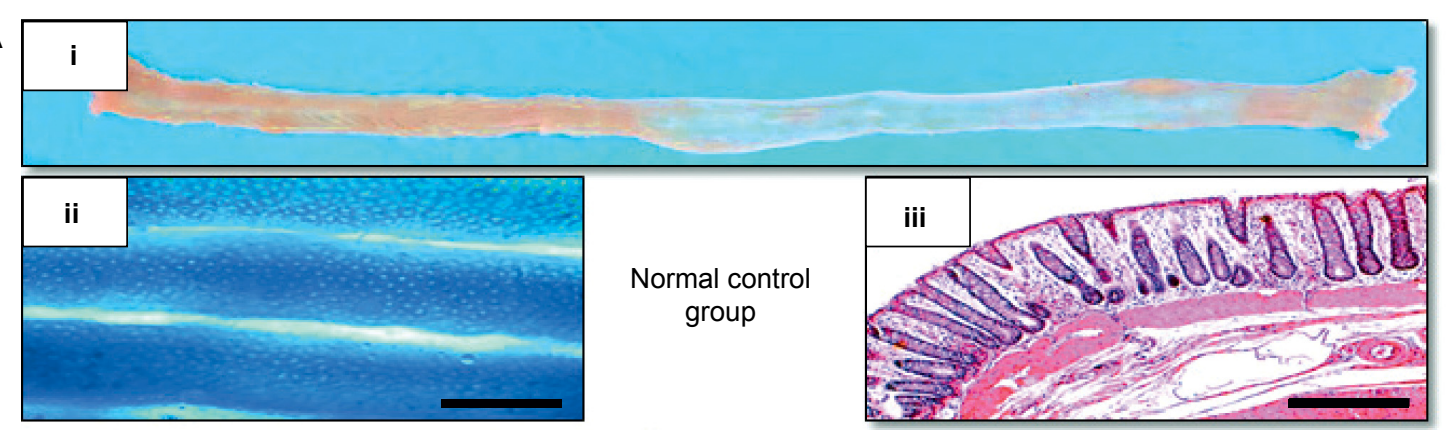

B
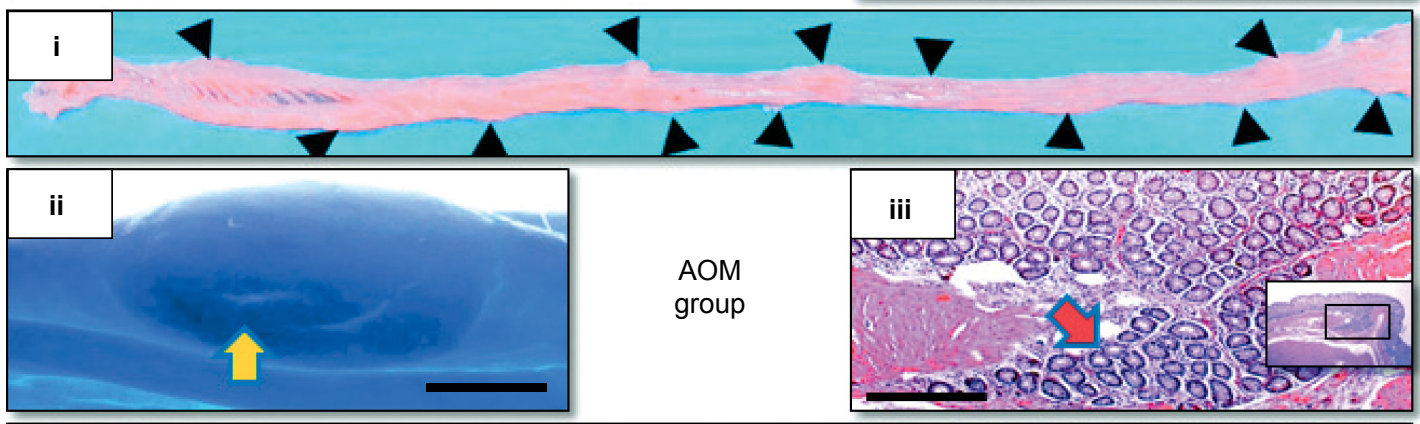

C
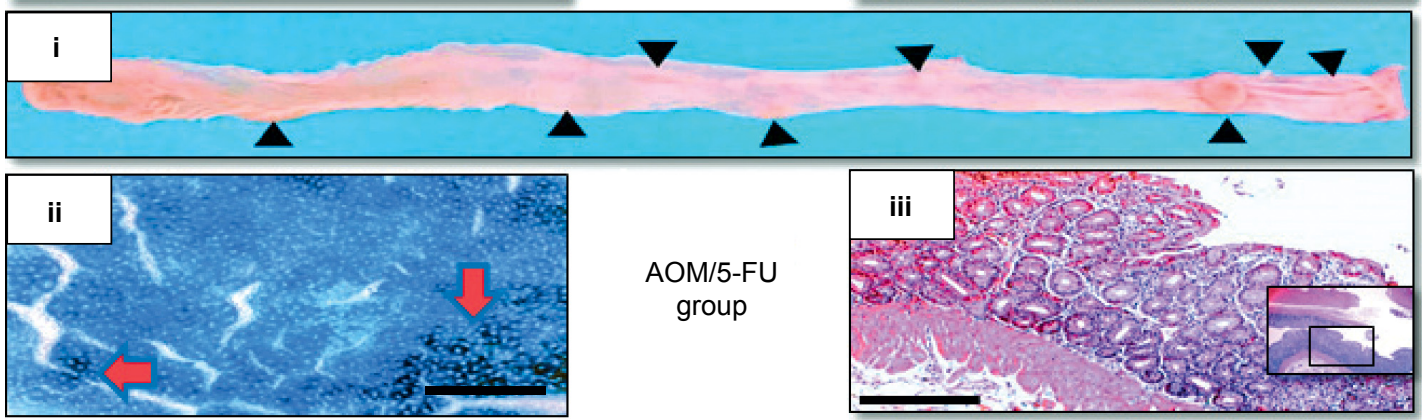

D
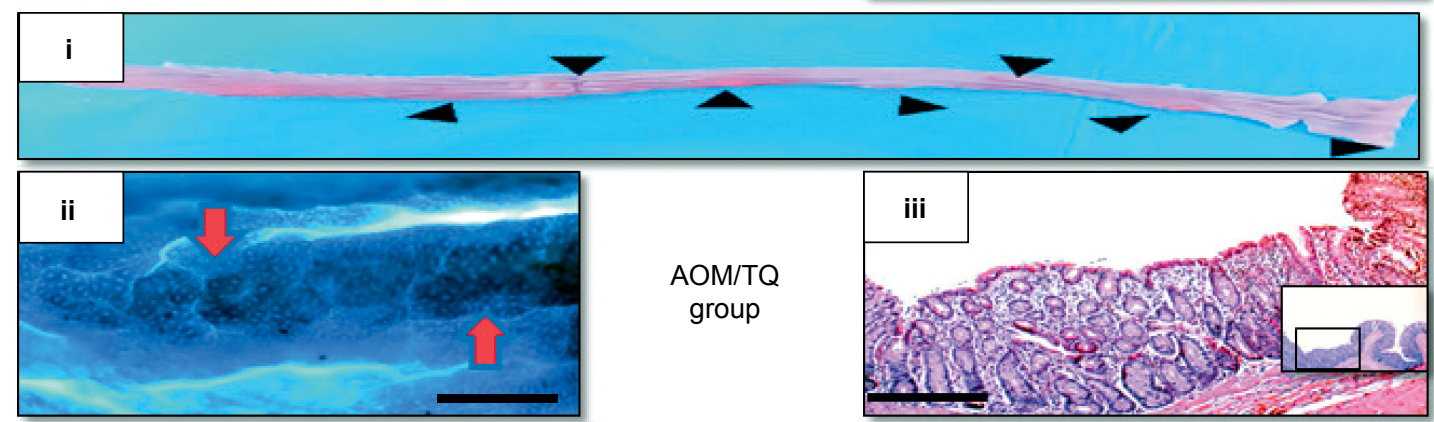

$\mathrm{AOM} / 5-\mathrm{FU}$

group

E

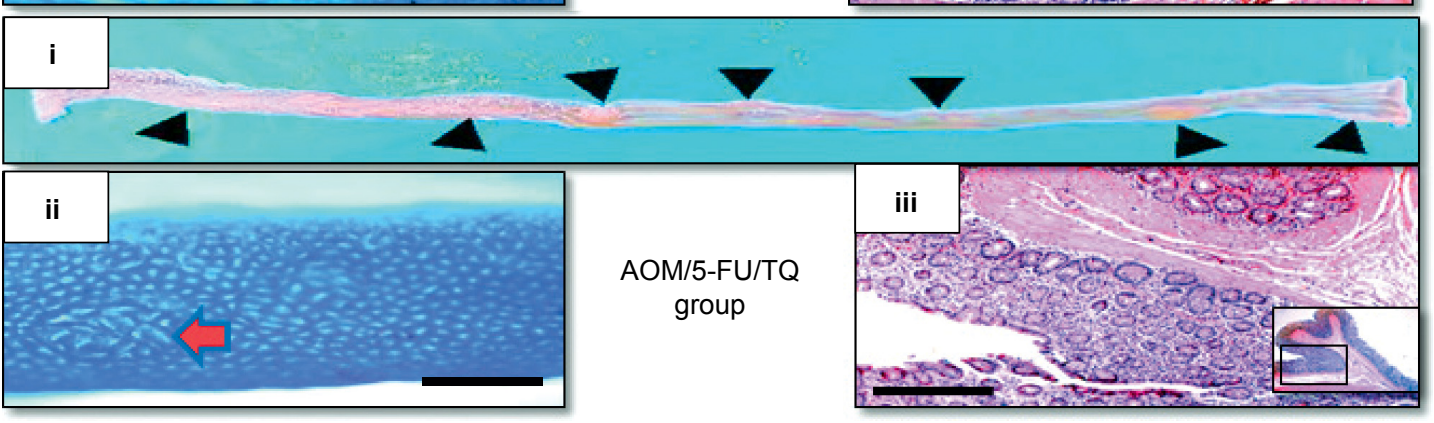

Figure I Representative photos of macroscopic and microscopic appearance of colorectal mucosa.

Notes: Shown are the pictures of normal control group (A), AOM group (B), AOM/5-FU group (C), AOM/TQ group (D), and AOM/5-FU/TQ group (E). The colorectal mucosa of the different groups was examined by naked eyes after formaline fixation (i); dissecting microscopy at magnifications $\times 100$ following staining with $0.2 \%$ methylene blue (ii), and light microscopy at magnifications $\times 100$ and $\times 200$ following staining with H\&E (iii). Black arrowheads: gross tumors observed by naked eye; yellow arrow: microtumor under dissecting microscopy; red arrows: large aberrant crypts foci (ACF) (containing four or more aberrant crypts). Scale bars $=8 \mu \mathrm{m}$.

Abbreviations: AOM, azoxymethane; 5-FU, 5-fluorouracil; TQ, thymoquinone; H\&E, hematoxylin and eosin. 
As demonstrated in Figure 2, qRT-PCR showed a remarkable elevation in the mRNA level of $W n t$ (Figure 2A), $\beta$-catenin (Figure 2B), $N F-\kappa B$ (Figure 2C), or COX-2 (Figure 2D), and a significant decrease in the mRNA level of $D K K-1$
(Figure 2E), CDNK-1A (Figure 2F), TGF- $\beta 1$ (Figure 2G), or Smad4 (Figure 2H) genes in the colorectal tissues of the AOM group compared with normal control group. On the contrary, co-therapy with TQ and 5-FU synergistically
A

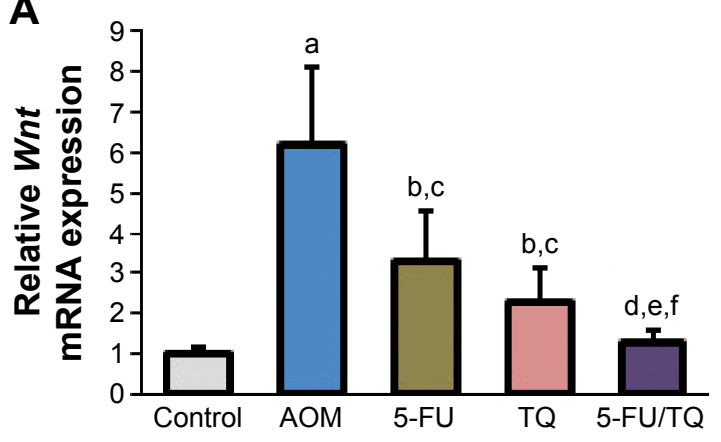

C

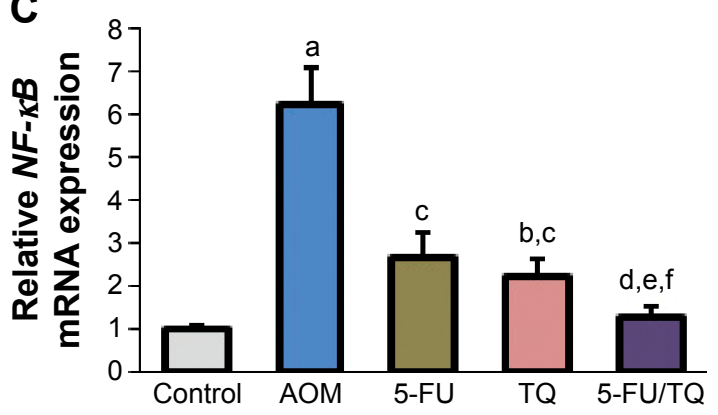

E

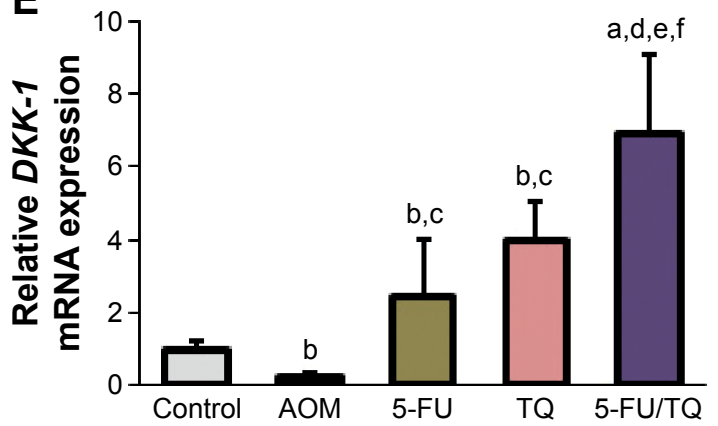

G

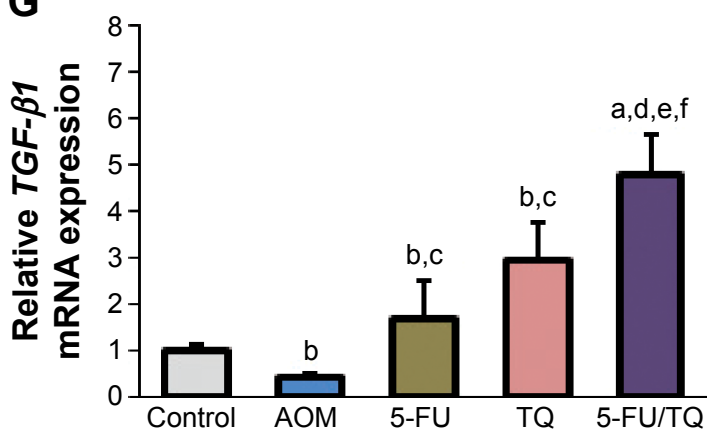

B

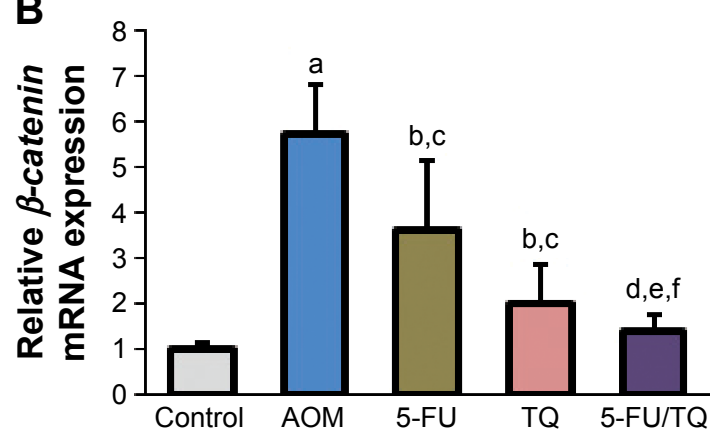

D

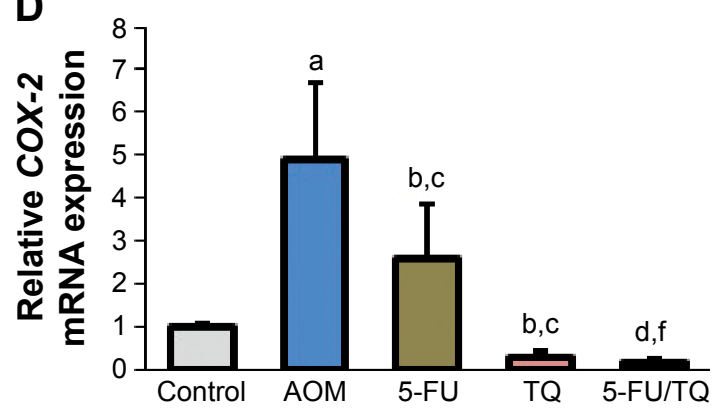

$\mathbf{F}$

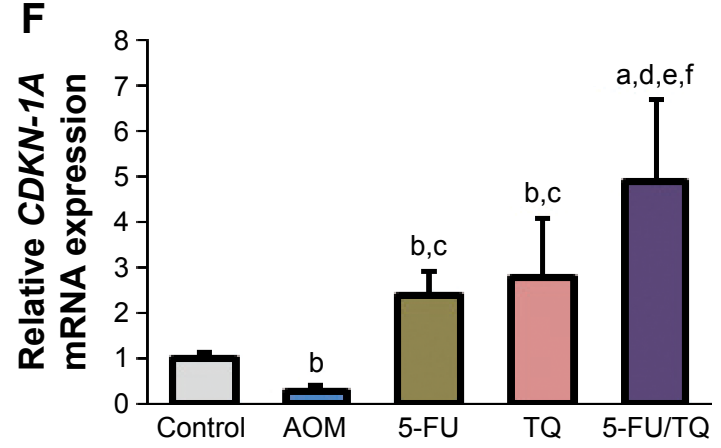

H

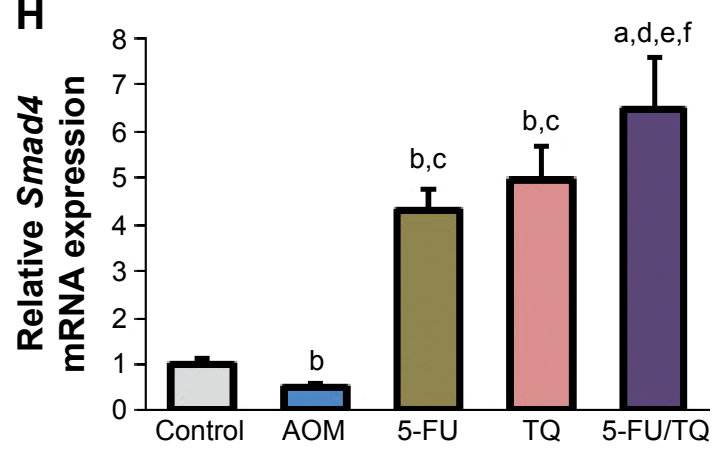

Figure 2 Findings of quantitative real-time polymerase chain reaction.

Notes: The figures show the modulatory effects of thymoquinone (TQ), 5-fluorouracil (5-FU), and their combination therapy on the relative mRNA expression of (A) Wnt, (B) $\beta$-catenin, (C) NF- KB, (D) COX-2, (E) DKK-I, (F) CDKN-IA, (G) TGF- $\beta I$, and (H) Smad4 genes in azoxymethane (AOM)-induced rat colorectal tumors. aP $<0.0 \mathrm{I}$ vs normal controls; ${ }^{b} P<0.05$ vs normal controls; ${ }^{c} P<0.05$ vs $A O M$ group; ${ }^{d} P<0.05$ vs $A O M / 5$-FU group; ${ }^{~} P<0.05$ vs $A O M / T Q$ group; and ${ }^{f} P<0.0$ I vs $A O M$ group. 
cooperated to modify the altered mRNA expression patterns of these pro-oncogenic and tumor suppressor genes in this AOM model of colorectal tumorigenesis (Figure $2 \mathrm{~A}-\mathrm{H}$ ).

\section{ELISA findings}

The colorectal levels of $\beta$-catenin, TGF- $\beta 1, \mathrm{COX}-2, \mathrm{VEGF}$, GPx, and TBARS were determined by ELISA. Figure 3 shows the significant effects of AOM on the induction of $\beta$-catenin (Figure 3A), COX-2 (Figure 3C), VEGF (Figure 3D), and TBARS (Figure 3F) in the colorectal tissues compared with the normal control group. However, the concentrations of these molecules were significantly reduced when the AOM-injected rats were subsequently treated with either TQ and/or 5-FU; and a more significant reduction was obtained with TQ and 5-FU combination therapy (Figure 3A, C, D, and F). In contrast to these data, the colorectal levels of TGF- $\beta 1$ (Figure 3B) and GPx (Figure 3E) were significantly decreased in the AOM group compared to the normal group. Interestingly, TQ and 5-FU acted synergistically not only to restore the expression levels of TGF- $\beta 1$ and GPx but also to upregulate their levels than those of normal controls (Figure 3B and E).

\section{Immunohistochemistry findings}

Next, IHC staining was performed to give further mechanistic insights. As shown in Figure 4 and Table 3, a remarkably low level of immunostaining for the TGF- $\beta 1$ system (TGF- $\beta 1$, TGF- $\beta$ RII, and Smad4) was detected in the glandular epithelium of the colorectal tissues of the AOM group in comparison with normal control group (Figure 4B, G, and L; Table 3). Though monotherapy with either 5-FU (Figure 4C, H, and M; Table 3) or TQ (Figure 4D, I, and N; Table 3) significantly counteracted the repression effect induced by AOM on these three elements of TGF- $\beta$ system, their single therapy failed to upregulate these repressed three TGF- $\beta$ candidate molecules to reach their levels in the normal control group (Table 3). On the other hand, combined therapy with TQ/5-FU interestingly cooperated to upregulate the expression pattern of TGF- $\beta 1$ (Figure 4E; Table 3), TGF-ßRII (Figure 4J; Table 3), or Smad4 (Figure 4O; Table 3) to reach a higher level compared to the control group (Table 3 ). In contrast to these data, the colorectal tissues of the AOM group showed marked elevations in the levels of $\beta$-catenin (Figure 5; Table 3 ) and iNOS (Figure 5G; Table 3) compared to their normal expression pattern in the colorectal tissues of control group (Figure 5A and F; Table 3); and therapy with TQ and 5-FU succeeded in repressing $\beta$-catenin and $\mathrm{iNOS}$ expression in a synergistic manner (Figure 5E and J; Table 3).

\section{Biochemical findings}

As shown in Table 2, the biochemical analysis of the collected sera samples did not show any significant differences in the serum levels of liver function enzymes and renal function parameters between the different animal groups, reflecting the safety profile, at least at the hepato-renal level, of the applied TQ/5-FU combination therapy.

\section{Discussion}

5-FU-based therapy is still the standard protocol used in the treatment of CRC. Nevertheless, its limited treatment response, dose-limiting toxicity, and resistance devolvement remain major challenges. ${ }^{3,4}$ Therefore, identifying a promising combination strategy to improve 5-FU's efficacy in CRC management is of paramount importance. TQ is a natural biological compound derived from $N$. sativa with wellknown, robust, and pluripotent antitumor activity. ${ }^{6-10} \mathrm{We}$ therefore investigated the in vivo ability of TQ to enhance the chemopreventive efficacy of 5-FU on an intermediate-term (15 weeks) model of colorectal tumorigenesis induced in rats by AOM, which is a commonly used in vivo experimental model because its different stages greatly mimic human CRC in several aspects. ${ }^{17,18}$ Interestingly, compared with the single therapy with either TQ or 5-FU, the two drugs remarkably cooperated to reduce the numbers of grown colorectal tumors and to inhibit the formation of microtumors and colonic preneoplastic lesions such as large ACF and MDF, which collectively represent the main macroscopic and microscopic features during this phase of colorectal tumorigenesis induced by AOM in rats. ${ }^{17,18}$ In support of our findings, earlier and recent in vitro studies have shown that TQ induces cellular damage on human colon cancer cells comparable to cells exposed to 5-FU. ${ }^{24}$ Furthermore, TQ has been found to promote the chemotherapeutic effectiveness of 5-FU on human nasopharyngeal carcinoma and gastric cancer, suggesting that TQ may be a potential adjuvant agent with 5-FU in cancer therapy. ${ }^{25,26}$ Of note, much effort has been spent on recognizing and identifying the common preneoplastic colorectal mucosal lesions during the early steps of colorectal carcinogenesis. In this regard, ACF identified in both humans and this AOM-animal model of CRC disease have been widely used as intermediate biomarkers of colorectal neoplasia and carcinogenesis and also to assess the preventive potential of several investigational chemopreventive agents. ${ }^{17,18}$ Furthermore, efforts to identify better precancerous lesions that strongly predict colorectal carcinogenesis than ACF have led to the identification of MDF characterized by the absence or scant production of mucin mucus. ${ }^{17}$ In the present study, 

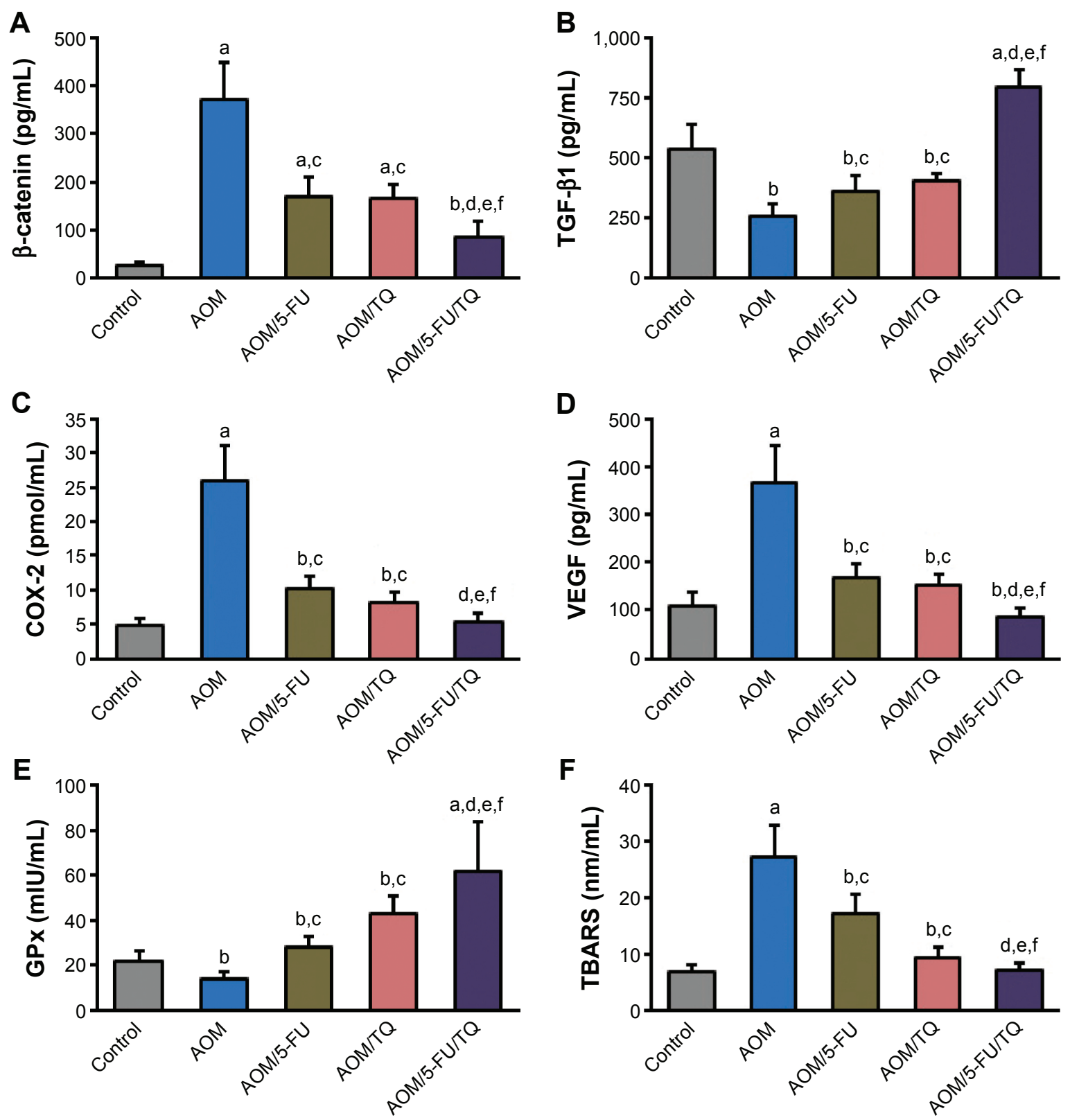

Figure 3 Enzyme-linked immunosorbent assay findings.

Notes: Shown are the modulatory effects of thymoquinone (TQ), 5 -fluorouracil (5-FU), and their combination therapy on the protein concentrations of (A) $\beta$-catenin, (B) TGF- $\beta$, (C) COX-2, (D) VEGF, (E) GPx, and (F) TBARS in the colorectal tissues of azoxymethane (AOM)-induced colorectal tumors in rats. Data are represented as mean \pm SD. ${ }^{\text {a }}<0.0$ I vs normal controls; ${ }^{b} P<0.05$ vs normal controls; ${ }^{c} P<0.05$ vs $A O M$ group; ${ }^{d} P<0.05$ vs $A O M / 5$-FU group; ${ }^{e}<<0.05$ vs $A O M / T Q$ group; ${ }^{f} P<0.0$ l vs $A O M$ group.

it was noticed that the combined therapy with 5-FU and TQ had markedly interfered with development of both ACF and MDF in the colorectal mucosa of rats injected with AOM, suggesting their potential chemopreventive interaction during the early stages of CRC disease.

At the molecular level, CRC is a multifaceted and multigenic malignant disease. Aberrant activation of the Wnt/ $\beta$-catenin signaling pathway and its downstream components has been suggested to be crucially implicated in the induction and dissemination of $\sim 80 \%$ of all human
CRCs. ${ }^{27,28}$ Mechanistically, this canonical tumorigenic pathway is initiated by binding of Wnt proteins with their target plasma membrane receptors/co-receptors, followed by the translocation of $\beta$-catenin into the nuclei of cells derived from the intestinal crypts wherein it stimulates the transcription of several pro-oncogenes. ${ }^{28}$ On the opposite side, $D K K-1$, a well-known colon cancer suppression agent, has been described as an important inhibitor of the $\mathrm{Wnt} / \beta$-catenin pathway by blocking Wnt signaling receptor complexes. ${ }^{29-31}$ Moreover, $D K K-1$ has also been suggested to 

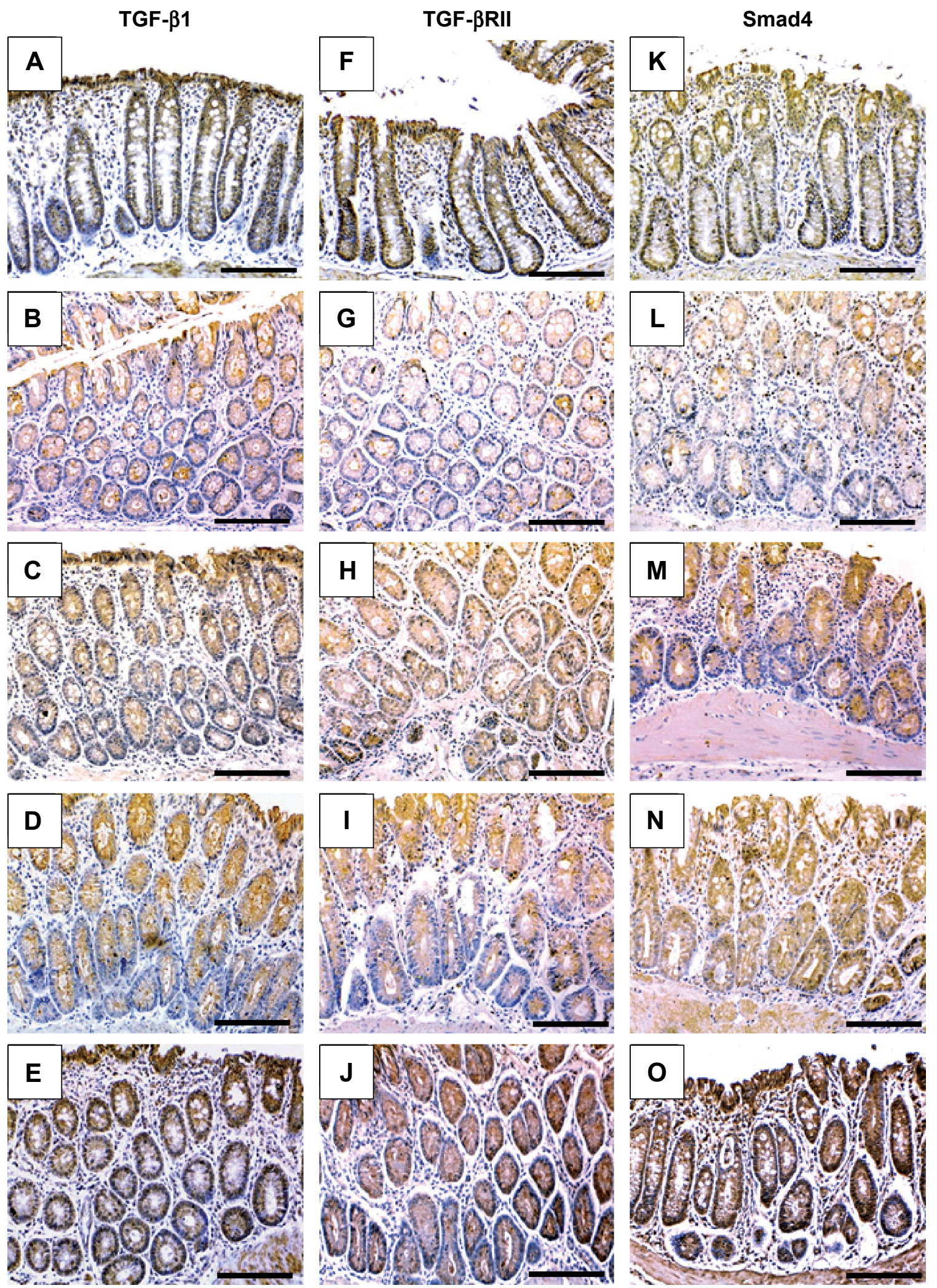

Figure 4 Representative photos of immunohistochemical findings.

Notes: The figures show the modulatory effects of thymoquinone (TQ), 5 -fluorouracil (5-FU), and their combination therapy on the protein concentrations of tissue growth factor- $\beta$ I (TGF- $\beta$ I; left column), TGF- $\beta$ receptor II (TGF- $\beta R$ II; middle column), and Smad4 (right column) in the colorectal tissues of normal control (A, F, and K), azoxymethane (AOM; B, G, and L), AOM treated with 5-fluorouracil (AOM + 5-FU; C, H, and M), AOM treated with thymoquinone (AOM + TQ; D, I, and $\mathbf{N}$ ), and AOM treated with 5-FU/TQ combination therapy $(\mathbf{E}, \mathbf{J}$, and $\mathbf{O})$ groups $(\times 200$ magnification and the scale bars are $8 \mu \mathrm{m})$. 
Table 3 Immunohistochemistry scores for the effects of thymoquinone (TQ) and/or 5-fluorouracil (5-FU)

\begin{tabular}{llllll}
\hline Parameter & Normal group & AOM group & AOM/5-FU group & AOM/TQ group & AOM/5-FU/TQ group \\
\hline TGF- $\beta I$ & $315.5 \pm 31.2$ & $136.4 \pm 23.4^{\mathrm{a}}$ & $301.48 \pm 44.3^{\mathrm{b}}$ & $307.3 \pm 37.2^{\mathrm{b}, \mathrm{c}}$ & $371.7 \pm 35.3^{\mathrm{a}-\mathrm{c}}$ \\
TGF- $\beta R I I$ & $333.7 \pm 28.7$ & $121.4 \pm 19.2^{\mathrm{a}}$ & $135.7 \pm 17.6^{\mathrm{a}}$ & $185.6 \pm 26.4^{\mathrm{a}-\mathrm{c}}$ & $305.4 \pm 31.8^{\mathrm{a}-\mathrm{d}}$ \\
Smad4 & $301.1 \pm 26$ & $147.2 \pm 20.3^{\mathrm{a}}$ & $216.1 \pm 23.9^{\mathrm{a}, \mathrm{b}}$ & $248.4 \pm 27.7^{\mathrm{a}-\mathrm{c}}$ & $322.7 \pm 31.5^{\mathrm{a}-\mathrm{d}}$ \\
$\beta-c a t e n i n$ & $61 \pm 16.7$ & $370.6 \pm 28.7^{\mathrm{a}}$ & $267.6 \pm 35.3^{\mathrm{a}, \mathrm{b}}$ & $251.6 \pm 35.1^{\mathrm{a}, \mathrm{b}}$ & $193.4 \pm 29.9^{\mathrm{a}-\mathrm{d}}$ \\
iNOS & $39.4 \pm 9.5$ & $373.1 \pm 26.8^{\mathrm{a}}$ & $261.8 \pm 47.2^{\mathrm{a}, \mathrm{b}}$ & $117.5 \pm 41.1^{\mathrm{a}-\mathrm{c}}$ & $79.5 \pm 22.3^{\mathrm{a}-\mathrm{d}}$ \\
\hline
\end{tabular}

Notes: The table shows the colorectal expression levels of tissue growth factor- $\beta$ I (TGF- $\beta$ I), TGF- $\beta$ receptor II (TGF- $\beta$ RII), Smad4, $\beta$-catenin, and inducible nitric oxide synthase (iNOS) in azoxymethane (AOM)-induced colorectal tumors in rats. Data are represented as mean \pm SD. a $P<0.05$ compared with normal control group. ${ }^{b} P<0.05$ compared with AOM group. ${ }^{c P}<0.05$ compared with 5 -FU group. ${ }^{d} P<0.05$ compared with $T Q$ group.

have additional Wnt/ $\beta$-catenin-independent tumor-suppressor, anti-angiogenesis, and anti-metastasis activities in CRC. ${ }^{30,32}$ In that respect, several colonic biopsies from CRC patients with chemoresistance and poor clinical outcome have shown a remarkable decrease in their colorectal levels of $D K K-1 .{ }^{28-31}$ Likewise, a remarkable downregulation or even loss of activity of CDNK-1A, a tumor suppressor gene that encodes a potent cell cycle inhibitory factor known as p21, has been detected in most human CRC cases. ${ }^{33,34}$ Based on these facts, it is conceivable that blocking or repression of the Wnt/ $\beta$ catenin pathway and/or stimulation of $D K K-1$ and CDNK-1A activity may hold tremendous therapeutic potential in CRC therapy. ${ }^{28-33}$ Interestingly, our findings are in harmony with this hypothesis, in that repression of $\mathrm{Wnt}$ and $\beta$-catenin and upregulation of activity of $D K K-1$ and CDNK-1A were significantly observed with TQ and 5-FU therapy and might be behind their observed augmented chemopreventive effect in this CRC model. In support, it has been reported that TQ attenuated colorectal tumor growth in $\mathrm{APC}^{\mathrm{Min}}$ mice by blocking the Wnt/ $\beta$-catenin pathway, ${ }^{35}$ and induced cell cycle arrest and DAN fragmentation in human CRC and other tumor cells via overexpression of $\mathrm{p} 21 .{ }^{14,36}$ Similarly, blockade of the $\mathrm{Wnt} / \beta$-catenin pathway has been associated with the inhibition of multidrug resistance system and cancer cell resistance to 5 -FU and other chemotherapeutics. ${ }^{37,38}$

$\mathrm{CRC}$ is a life-threatening complication of inflammatory bowel diseases. In this regard, the aberrant activation of NF- $\mathrm{KB}$ and overproduction of pro-oncogenic inflammatory mediators such as COX-2 and iNOS may provide a crucial mechanistic link between inflammation and carcinogenesis. ${ }^{39-42}$ Aberrant activation of NF- $\kappa \mathrm{B}$ can induce many tumorigenesis genes that influence tumor growth, angiogenesis, invasion, resistance to chemotherapy, and other potentially carcinogenic processes. ${ }^{43}$ As well, overexpression of COX-2 and iNOS and the induction of lipid peroxidation and oxidative stress have been shown to play vital roles between colorectal inflammation and carcinogenicity. $40-45$
Like other cancers, angiogenesis mediated by VEGF and other pivotal angiogenic and tumor vascularization facilitators has a central role in the progression and metastasis of CRC. ${ }^{46}$ Taken together, suppression of NF- $\kappa B$, iNOS, COX-2, VEGF, and/or lipid peroxidation could represent a potential strategy in CRC therapy. Interestingly, our data are in harmony and showed that TQ/5-FU combination therapy significantly suppressed AOM-induced lipid peroxidation and the expression of NF- $\mathrm{B}$, iNOS, COX-2, and VEGF in the colorectal tissues. In agreement, results from previous studies have indicated that the anticancer and anti-inflammatory activities of TQ might be mediated in part through the suppression of NF- $\mathrm{KB}$, iNOS, and COX-2 activation pathways and tumor angiogenesis, in addition to its potent antioxidant and tissue protective property. ${ }^{9,10,47}$ Furthermore, 5-FU has been shown to inhibit the NF- $\kappa B$ pathway and NF- $\mathrm{KB}-$ mediated $\mathrm{NO}$ production in cancer cells, ${ }^{48,49}$ and selective inhibition of NF- $\kappa$ B and COX-2 has shown to enhance the in vitro cytotoxic effects of 5-FU on CRC cells and downregulate VEGF production and vascular density in tumor tissues. ${ }^{40,50,51}$

TGF- $\beta 1$ is a pleiotropic cytokine engaged in several cellular functions and processes. Importantly, dysfunction of the TGF- $\beta 1$ signaling pathway is crucially involved in a variety of diseases including cancer, and its dual paradoxical roles have been well established in variable cancers, though the precise underlying mechanisms of this paradox have remained elusive. ${ }^{52-55}$ Of note, the activation of this pathway and its downstream components during the early stages of oncogenesis is generally associated with oncosuppression and the inhibition of epithelial cell transformation and hyperproliferation. ${ }^{53,54}$ The pleiotropic activities of TGF- $\beta 1$ are mediated through Smad-dependent and independent mechanisms depending upon the cellular subset in which this cytokine exerts its actions. ${ }^{55,56}$ In the Smad-dependent pathway, signaling begins with the binding of TGF- $\beta 1$ to its receptor (TGF- $\beta$ RII) with downstream activation of complex pathways 

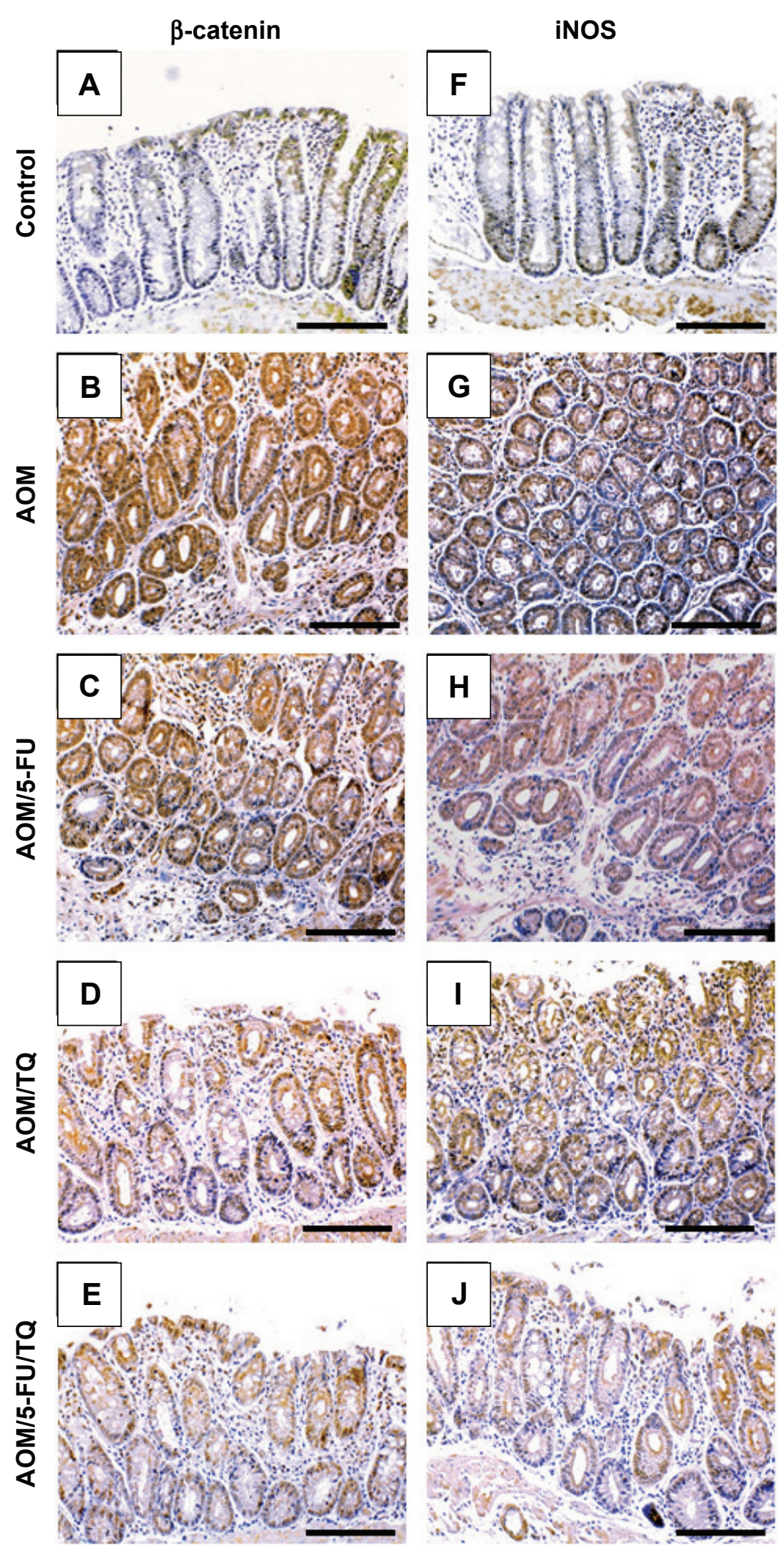

Figure 5 Representative photos of immunohistochemical findings.

Notes: The pictures show the regulatory effects of thymoquinone (TQ), 5 -fluorouracil (5-FU), and their combination therapy on the protein concentrations of $\beta$-catenin and inducible nitric oxide synthase (iNOS) in the colorectal tissues of normal control (A and F), azoxymethane (AOM; B and $\mathbf{G})$, AOM treated with 5 -fluorouracil (AOM + 5-FU; $\mathbf{C}$ and $\mathbf{H})$, AOM treated with thymoquinone (AOM + TQ; $\mathbf{D}$ and I), and AOM treated with 5-FU/TQ combination therapy $(\mathbf{E}$ and $\mathbf{J})$ groups $(\times 200$ magnification and the scale bar is $8 \mu \mathrm{m})$.

Abbreviation: iNOS, inducible nitric oxide synthase. 
involving co-Smads, particularly Smad4, to transduce the signal into the nucleus and influence the transcription of several target genes. ${ }^{53-56}$ Considerably, earlier studies have shown that downregulation or loss of TGF- $\beta 1$ and its receptors leads to increased susceptibility to gastrointestinal carcinogenesis, particularly colon cancer. ${ }^{54}$ Moreover, downregulation or even loss of the Smad4 protein has been clinically detected in CRC and other neoplastic diseases, and would be used as a valuable prognostic factor. ${ }^{56}$ On the other hand, the upregulation of this pathway has been previously explored as a part of the antitumor mechanisms of TQ therapy on human pancreatic and breast cancers, ${ }^{57,58}$ and 5-FU-exhibited activation of TGF- $\beta$ pathway has been observed in human CRC cells both in vitro and in a xenograft model. ${ }^{59}$ Interestingly, findings of the present study are in parallel, and demonstrate that combination therapy with TQ and 5-FU not only recovers AOM-induced suppression of TGF- $\beta 1$, TGF- $\beta$ RII, and Smad4 expression in the colorectal tissues but also to upregulate their levels more than those of normal controls, suggesting that the enhancement of TGF- $\beta 1$-Smad4-dependent pathway could be a part of the underlying mechanisms by which TQ and 5-FU displayed their observed augmenting antitumor effect on this preclinical model of CRC disease.

\section{Conclusion}

The present study demonstrates the positive chemopreventive interaction between TQ and 5-FU against the early stages of colorectal tumors induced by AOM in rats by modulating the expression pattern of a number of pro and anticancerous pathways and molecules. Further studies are warranted to illustrate the reality of its clinical value and also to explore its possible usefulness in advanced stages of this dark cancer.

\section{Acknowledgments}

This project was funded by the National Science, Technology and Innovation Plan of (MARRIFAH)-King Abdul Aziz City for Science and Technology (KACST), the Kingdom of Saudi Arabia, Award Number (12-MED2965-10). OAK, AGE, BR, and AMM are the recipients of the grant.

\section{Author contributions}

$\mathrm{OAK}$ and AGE conceived and conceptualized the study and its design. All authors participated in the study methodologies and laboratory processes and analysis and interpretation of the results. All authors contributed toward drafting and critically revising the paper, gave final approval of the version to be published, and agree to be accountable for all aspects of the work.

\section{Disclosure}

The authors report no conflicts of interest in this work.

\section{References}

1. Rouhollahi E, Moghadamtousi SZ, Al-Henhena N, et al. The chemopreventive potential of Curcuma purpurascens rhizome in reducing azoxymethane-induced aberrant crypt foci in rats. Drug Des Devel Ther. 2015;9:3911-3922.

2. Ferlay J, Soerjomataram I, Dikshit R, et al. Cancer incidence and mortality worldwide: sources, methods and major patterns in GLOBOCAN 2012. Int J Cancer. 2015;136(5):E359-E386.

3. Ahn JY, Lee JS, Min HY, Lee HY. Acquired resistance to 5-fluorouracil via HSP90/Src-mediated increase in thymidylate synthase expression in colon cancer. Oncotarget. 2015;6(32):32622-32633.

4. Hammond WA, Swaika A, Mody K. Pharmacologic resistance in colorectal cancer: a review. Ther Addv Med Oncol. 2016;8(1):57-84.

5. Stringer AM, Gibson RJ, Bowen JM, Keefe DM. Chemotherapyinduced modifications to gastrointestinal microflora: evidence and implications of change. Curr Drug Metab. 2009;10(1):79-83.

6. Agbaria R, Gabarin A, Dahan A, Ben-Shabat S. Anticancer activity of Nigella sativa (black seed) and its relationship with the thermal processing and quinone composition of the seed. Drug Des Devel Ther. 2015; 9:3119-3124.

7. Darakhshan S, Bidmeshki Pour A, Hosseinzadeh Colagar A, Sisakhtnezhad S. Thymoquinone and its therapeutic potentials. Pharmacol Re. 2015;95-96:138-158.

8. Barakat EM, El Wakeel LM, Hagag RS. Effects of Nigella sativa on outcome of hepatitis C in Egypt. World J Gastroenterol. 2013;19(16): 2529-2536.

9. Rahmani AH, Alzohairy MA, Khan MA, Aly SM. Therapeutic implications of black seed and its constituent thymoquinone in the prevention of cancer through inactivation and activation of molecular pathways. Evid Based Complement Alternat Med. 2014;2014:724658.

10. Abukhader MM. Thymoquinone in the clinical treatment of cancer: fact or fiction? Pharmacogn Rev. 2013;7(14):117-120.

11. Li F, Rajendran P, Sethi G. Thymoquinone inhibits proliferation, induces apoptosis and chemosensitizes human multiple myeloma cells through suppression of signal transducer and activator of transcription 3 activation pathway. Br J Pharmacol. 2010;161(3):541-554.

12. Attoub S, Sperandio O, Raza H, et al. Thymoquinone as an anticancer agent: evidence from inhibition of cancer cells viability and invasion in vitro and tumor growth in vivo. Fundam Clin Pharmacol. 2013;27(5):557-569.

13. Kundu J, Chun KS, Aruoma OI, Kundu JK. Mechanistic perspectives on cancer chemoprevention/chemotherapeutic effects of thymoquinone. Mutat Res. 2014;768:22-34.

14. Khalife R, Hodroj MH, Fakhoury R, Rizk S. Thymoquinone from Nigella sativa seeds promotes the antitumor activity of noncytotoxic doses of topotecan in human colorectal cancer cells in vitro. Planta Med. 2016;82(4):312-321.

15. Akhondian J, Kianifar H, Raoofziaee M, Moayedpour A, Toosi MB, Khajedaluee M. The effect of thymoquinone on intractable pediatric seizures (pilot study). Epilepsy Res. 2011;93(1):39-43.

16. Chen MC, Lee NH, Hsu HH, et al. Thymoquinone induces caspaseindependent, autophagic cell death in CPT-11-resistant lovo colon cancer via mitochondrial dysfunction and activation of JNK and $\mathrm{p} 38$. J Agric Food Chem. 2015;63(5):1540-1546.

17. Washington MK, Powell AE, Sullivan R, et al. Pathology of rodent models of intestinal cancer: progress report and recommendations. Gastroenterology. 2013;144(4):705-717.

18. Almagrami AA, Alshawsh MA, Saif-Ali R, Shwter A, Salem SD, Abdulla MA. Evaluation of chemopreventive effects of Acanthus ilicifolius against azoxymethane-induced aberrant crypt foci in the rat colon. PLoS One. 2014;9:e96004.

19. Khazdair MR. The protective effects of Nigella sativa and its constituents on induced neurotoxicity. $J$ Toxicol. 2015;2015:841823. 
20. Guan F, Li G, Liu AB, et al. $\delta$ - and $\gamma$-tocopherols, but not $\alpha$-tocopherol, inhibit colon carcinogenesis in azoxymethane-treated F344 rats. Cancer Prev Res (Phila). 2012;5(4):644-654.

21. Xiao H, Hao X, Simi B, et al. Green tea polyphenols inhibit colorectal aberrant crypt foci (ACF) formation and prevent oncogenic changes in dysplastic ACF in azoxymethane-treated F344 rats. Carcinogenesis. 2008;29(1):113-119.

22. Livak KJ, Schmittgen TD. Analysis of relative gene expression data using real-time quantitative PCR and the 2(-Delta Delta C(T)) method. Methods. 2001;25(4):402-408.

23. Prakash A, Tuckerman E, Laird S, Ola B, Li TC, Ledger WL. A preliminary study comparing the endometrial expression of inhibin, activin and follistatin in women with a history of implantation failure after IVF treatment and a control group. BJOG. 2008;115(4):532-536; discussion 536-537.

24. Norwood AA, Tan M, May M, Tucci M, Benghuzzi H. Comparison of potential chemotherapeutic agents, 5-fluoruracil, green tea, and thymoquinone on colon cancer cells. Biomed Sci Instrum. 2006;42: 350-356.

25. Williams S, Tucci MA, Benghuzzi HA. The effect of combination treatments of epigallocatechin-3-gallate, thymoquinone, and 5-fluorouracil on fadu nasopharyngeal carcinoma cells. Biomed Sci Instrum. 2014;50: 361-366.

26. Lei $X, L v X$, Liu M, et al. Thymoquinone inhibits growth and augments 5-fluorouracil-induced apoptosis in gastric cancer cells both in vitro and in vivo. Biochem Biophys Res Commun. 2012;417(2):864-868.

27. Song L, Li ZY, Liu WP, Zhao MR. Crosstalk between Wnt/ $\beta$-catenin and Hedgehog/Gli signaling pathways in colon cancer and implications for therapy. Cancer Biol Ther. 2015;16(1):1-7.

28. Fonseca BF, Predes D, Cerqueira DM, et al. Derricin and derricidin inhibit Wnt/ $\beta$-catenin signaling and suppress colon cancer cell growth in vitro. PLoS One. 2015;10(3):e0120919.

29. Niehrs C. Function and biological roles of the Dickkopf family of Wnt modulators. Oncogene. 2006;25(57):7469-7481.

30. Qi L, Sun B, Liu Z, Li H, Gao J, Leng X. Dickkopf-1 inhibits epithelialmesenchymal transition of colon cancer cells and contributes to colon cancer suppression. Cancer Sci. 2012;103(4):828-835.

31. Aguilera Ó, González-Sancho JM, Zazo S, et al. Nuclear DICKKOPF-1 as a biomarker of chemoresistance and poor clinical outcome in colorectal cancer. Oncotarget. 2015;6(8):5903-5917.

32. Liu Z, Sun B, Qi L, et al. Dickkopf-1 expression is down-regulated during the colorectal adenoma-carcinoma sequence and correlates with reduced microvessel density and VEGF expression. Histopathology. 2015;67(2): $158-166$.

33. Ogino S, Nosho K, Shima K, et al. p21 expression in colon cancer and modifying effects of patient age and body mass index on prognosis. Cancer Epidemiol Biomarkers Prev. 2009;18(9):2513-2521.

34. Bishehsari F, Gach JS, Akagi N, Webber MK, Bauer J, Jung BH. Antip21 autoantibodies detected in colorectal cancer patients: a proof of concept study. Oncoimmunology. 2014;3(8):e952202.

35. Lang M, Borgmann $\mathrm{M}$, Oberhuber $\mathrm{G}$, et al. Thymoquinone attenuates tumor growth in ApcMin mice by interference with Wnt-signaling. Mol Cancer. 2013;12(1):41.

36. Paramasivam A, Raghunandhakumar S, Priyadharsini JV, Jayaraman G. In vitro anti-neuroblastoma activity of thymoquinone against neuro-2a cells via cell-cycle arrest. Asian Pac J Cancer Prev. 2015;16(18): 8313-8319.

37. Noda T, Nagano H, Takemasa I, et al. Activation of Wnt/betacatenin signalling pathway induces chemoresistance to interferonalpha/5-fluorouracil combination therapy for hepatocellular carcinoma. Br J Cancer. 2009;100(10):1647-1658.

38. Shen DY, Zhang $W$, Zeng X, Liu CQ. Inhibition of Wnt/ $\beta$-catenin signaling downregulates $\mathrm{P}$-glycoprotein and reverses multi-drug resistance of cholangiocarcinoma. Cancer Sci. 2013;104(10):1303-1308.

39. DiDonato JA, Mercurio F, Karin M. NF-kappaB and the link between inflammation and cancer. Immunol Rev. 2012;246(1):379-400.
40. Ranger GS. Current concepts in colorectal cancer prevention with cyclooxygenase inhibitors. Anticancer Res. 2014;34(11):6277-6282.

41. Janakiram NB, Rao CV. The role of inflammation in colon cancer. $A d v$ Exp Med Biol. 2014;816:25-52.

42. Campanholo VM, Silva RM, Silva TD, et al. Oral concentrated grape juice suppresses expression of NF-kappa B, TNF- $\alpha$ and iNOS in experimentally induced colorectal carcinogenesis in Wistar rats. Asian Pac J Cancer Prev. 2015;16(3):947-952.

43. Li F, Zhang J, Arfuso F, et al. NF-kappaB in cancer therapy. Arch Toxicol. 2015;89(5):711-731.

44. Waly MI, Al-Rawahi AS, Al Riyami M, et al. Amelioration of azoxymethane induced-carcinogenesis by reducing oxidative stress in rat colon by natural extracts. BMC Complement Altern Med. 2014; $14: 60$.

45. Afrin S, Giampieri F, Gasparrini M, et al. Chemopreventive and therapeutic effects of edible berries: a focus on colon cancer prevention and treatment. Molecules. 2016;21(2):169.

46. Zhou LH, Hu Q, Sui H, et al. Tanshinone II-a inhibits angiogenesis through down regulation of COX-2 in human colorectal cancer. Asian Pac J Cancer Prev. 2012;13(9):4453-4458.

47. Harzallah HJ, Grayaa R, Kharoubi W, Maaloul A, Hammami M, Mahjoub T. Thymoquinone, the Nigella sativa bioactive compound, prevents circulatory oxidative stress caused by 1,2-dimethylhydrazine in erythrocyte during colon postinitiation carcinogenesis. Oxid Med Cell Longev. 2012;2012:854065.

48. Jung ID, Yang SY, Park CG, et al. 5-Fluorouracil inhibits nitric oxide production through the inactivation of IkappaB kinase in stomach cancer cells. Biochem Pharmacol. 2002;64(10):1439-1445.

49. Aota K, Azuma M, Yamashita T, et al. 5-Fluorouracil induces apoptosis through the suppression of NF-kappaB activity in human salivary gland cancer cells. Biochem Biophys Res Commun. 2000;273(3): $1168-1174$.

50. Irie T, Tsujii M, Tsuji S, et al. Synergistic antitumor effects of celecoxib with 5-fluorouracil depend on IFN-gamma. Int J Cancer. 2007;121(4): $878-883$.

51. Voboril R, Hochwald SN, Li J, et al. Inhibition of NF-kappa B augments sensitivity to 5 -fluorouracil/folinic acid in colon cancer. $J$ Surg Res. 2004;120(2):178-188.

52. Smith AL, Robin TP, Ford HL. Molecular pathways: targeting the TGF- $\beta$ pathway for cancer therapy. Clin Cancer Res. 2012;18(17): 4514-4521.

53. Principe DR, Doll JA, Bauer J, et al. TGF- $\beta$ : duality of function between tumor prevention and carcinogenesis. J Natl Cancer Inst. 2014; 106(2):djt369.

54. Hahm KB, Lee KM, Kim YB, et al. Conditional loss of TGF-beta signalling leads to increased susceptibility to gastrointestinal carcinogenesis in mice. Aliment Pharmacol Ther. 2002;16(suppl 2):115-127.

55. Zhang Q, Yu N, Lee C. Mysteries of TGF- $\beta$ paradox in benign and malignant cells. Front Oncol. 2014;4:94.

56. Witkowska M, Smolewski P. SMAD family proteins: the current knowledge on their expression and potential role in neoplastic diseases. Postepy Hig Med Dosw (Online). 2014;68:301-309.

57. Torres MP, Ponnusamy MP, Chakraborty S, et al. Effects of thymoquinone in the expression of mucin 4 in pancreatic cancer cells: implications for the development of novel cancer therapies. Mol Cancer Ther. 2010;9(5):1419-1431.

58. Rajput S, Kumar BN, Dey KK, Pal I, Parekh A, Mandal M. Molecular targeting of Akt by thymoquinone promotes $\mathrm{G}(1)$ arrest through translation inhibition of cyclin D1 and induces apoptosis in breast cancer cells. Life Sci. 2013;93(21):783-790.

59. Romano G, Santi L, Bianco MR, et al. The TGF- $\beta$ pathway is activated by 5 -fluorouracil treatment in drug resistant colorectal carcinoma cells. Oncotarget. Epub 2016 Mar 3. 


\section{Supplementary material}

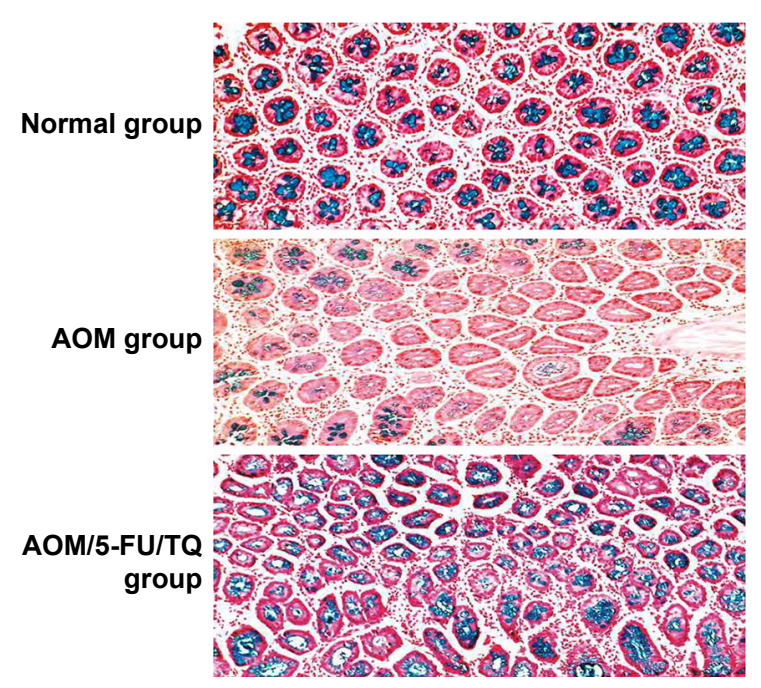

Figure SI Corresponding histopathological features of colorectal tissues stained with Alcian blue.

Notes: The figure shows the pre-neoplastic mucin-depleted foci (MDF) that had lost mucin expression (blue color) and was abundantly present in the colorectal tissues of rats injected with azoxymethane and left without treatment (AOM group) but not in rats injected with AOM and then treated with TQ and 5-FU combination therapy. Light microscopy at magnifications $\times 2,000$.

Abbreviations: AOM, azoxymethane; TQ, thymoquinone; 5-FU, 5-fluorouracil.

\section{Publish your work in this journal}

Drug Design, Development and Therapy is an international, peerreviewed open-access journal that spans the spectrum of drug design and development through to clinical applications. Clinical outcomes, patient safety, and programs for the development and effective, safe, and sustained use of medicines are a feature of the journal, which has also been accepted for indexing on PubMed Central. The manuscript management system is completely online and includes a very quick and fair peer-review system, which is all easy to use. Visit http://www.dovepress.com/testimonials.php to read real quotes from published authors.

Submit your manuscript here: http://www.dovepress.com/drug-design-development-and-therapy-journal 